\title{
Growth on Carbohydrates from Carbonaceous Meteorites Alters the Immunogenicity of Environment-Derived Bacterial Pathogens
}

\author{
Jorge Domínguez-Andrés, ${ }^{1-3,{ }^{*}}$ Marc Eleveld, ${ }^{2,4, *}$ Georgios Renieris, ${ }^{5}$ Thomas J. Boltje, ${ }^{6}$ \\ Rob J. Mesman, ${ }^{7}$ Laura van Niftrik, ${ }^{7}$ Sam J. Moons, ${ }^{6}$ Petra Rettberg, ${ }^{8}$ Jos W.M. van der Meer, ${ }^{1,2}$ \\ Evangelos J. Giamarellos-Bourboulis, ${ }^{5}$ Huub J.M. Op den Camp, ${ }^{7}$ \\ Marien I. de Jonge, ${ }^{2,4, \dagger}$ and Mihai G. Netea ${ }^{1-3,9, \dagger}$
}

\begin{abstract}
The last decade has witnessed a renewed interest in space exploration. Public and private institutions are investing considerable effort toward the direct exploration of the Moon and Mars, as well as more distant bodies in the solar system. Both automated and human-crewed spacecraft are being considered in these efforts. As inevitable fellow travelers on the bodies of astronauts, spaceships, or equipment, terrestrial microorganisms will undoubtedly come into contact with extraterrestrial environments, despite stringent decontamination. These microorganisms could eventually adapt and grow in their new habitats, where they might potentially recolonize and lead to the infection of the human space travelers. In this article, we demonstrate that clinically relevant bacterial species found in the environment are able to grow in minimal media with sugar compounds identified in extraterrestrial carbon sources. As a surrogate model, we used carbohydrates previously isolated from carbonaceous meteorites. The bacteria underwent an adaptation process that caused structural modifications in the cell envelope that sparked changes in pathogenic potential, both in vitro and in vivo. Understanding the adaptation of microorganisms exposed to extraterrestrial environments, with subsequent changes in their immunogenicity and virulence, requires a comprehensive analysis of such scenarios to ensure the safety of major space expeditions in the decades to come. Key Words: Space exploration-Microorganisms-ImmunityCytokines-Meteorites-Bacteria. Astrobiology 20, 1353-1362.
\end{abstract}

\section{Introduction}

M ICROORGANISMS ARE EXTREMELY resistant and adaptable, being the only type of organisms that can survive under extreme conditions of temperature, $\mathrm{pH}$, radiation, or pressure (Seckbach and Oren, 2000; Pulschen et al., 2018). Traveling on the bodies of astronauts, future space tourists, or spacecrafts, terrestrial environmental microorganisms are likely to come into contact with new extraterrestrial environments, despite measures to prevent contamination. The rise in space expeditions will increase the chance that extraterrestrial destinations will be contaminated with terrestrial microorganisms. The harsh conditions of space are harmful to most organisms, but it may not kill all of them. One group of nonfastidious, pathogenic bacteria can be found in the soil and open water. Although the habitability of extraterrestrial

${ }^{1}$ Department of Internal Medicine, Radboud University Medical Center, Nijmegen, Netherlands.

${ }^{2}$ Radboud Center for Infectious Diseases, Radboud University Medical Center, Nijmegen, Netherlands.

${ }^{3}$ Radboud Institute for Molecular Life Sciences, Radboud University Medical Center, Nijmegen, Netherlands.

${ }^{4}$ Section Pediatric Infectious Diseases, Laboratory of Medical Immunology, Department of Laboratory Medicine, Radboud University Medical Center, Nijmegen, Netherlands.

${ }_{5} 4$ th Department of Internal Medicine, National and Kapodistrian University of Athens, Medical School, Athens, Greece.

${ }^{6}$ Institute for Molecules and Materials, Radboud University, Nijmegen, Netherlands.

${ }^{7}$ Department of Microbiology, Institute for Water and Wetland Research, Faculty of Science, Radboud University, Nijmegen, Netherlands.

${ }^{8}$ Research Group Astrobiology, Radiation Biology Department, Institute of Aerospace Medicine, Deutsches Zentrum für Luft- und Raumfahrt e.V. (DLR), Köln, Germany.

${ }^{9}$ Department for Genomics \& Immunoregulation, Life and Medical Sciences Institute (LIMES), University of Bonn, Bonn, Germany.

*Both these authors contributed equally to this work.

${ }^{\dagger}$ Both these authors share senior authorship. 
environments for bacterial species might be limited, such environments could potentially induce a dormant state, which could subsequently lead to revival under favorable living conditions (Nicholson et al., 2000; Nagler et al., 2016).

Water can be found in primitive structures (e.g., comets and asteroids), and large water oceans under thick ice caps have been identified on planets (e.g., Mars), as well as on satellites of the gaseous giants, including Europa (the smallest of four Galilean moons orbiting Jupiter) and Enceladus (the sixth largest moon of Saturn) (Parkinson et al., 2008; Waite et al., 2009). In addition, studies of carbonaceous meteorites originating in the asteroid belt have detected large amounts of organic compounds (e.g., amino acids, nucleobases, and polyols), including sugars, sugar alcohols, and sugar acids (Cooper and Rios, 2016; Pizzarello and Shock, 2017). Such organic materials are likely to exist on other bodies in the solar system as well. Simulations of interstellar conditions have indicated that photolysis of small molecules can generate polyols of low molecular weight (Agarwal et al., 1985; Khare et al., 1989), which could also serve as basic nutrients for microorganisms. Water and similar organic compounds could thus fulfill the nutritional requirements of terrestrial microorganisms that have the potential to adapt to the harsh conditions of space (Pering and Ponnamperuma, 1971; Cronin and Pizzarello, 1997).

\section{Materials and Methods}

\subsection{Bacterial growth assessment}

Bacterial strains were ordered from DSMZ: Pseudomonas aeruginosa (DSM-22644), Serratia marcescens (DSM30121), Burkholderia cepacia (DSM-7288), and Klebsiella pneumoniae (DSM-30104). All species were plated on nutrient-broth (Difco) agar plates. After o/n growth at $35^{\circ} \mathrm{C}$, several colonies were resuspended in M9-complete ([M9


$2 \mathrm{mM} \mathrm{MgSO}_{4}$, and $0.02 \mathrm{mM} \mathrm{Fe}(\mathrm{III}) \mathrm{Cl}_{3}$ ], $47.8 \mathrm{mM} \mathrm{Na} \mathrm{HPO}_{4}$, $22.0 \mathrm{mM} \mathrm{KH} \mathrm{KH}_{4}, 8.6 \mathrm{mM} \mathrm{NaCl}$, and $3.7 \mathrm{mM} \mathrm{NH} \mathrm{PH}_{4}$, without carbon source). Thereafter, optical density at $600 \mathrm{~nm}\left(\mathrm{OD}_{600}\right)$ was measured, and bacteria were diluted to a starting $\mathrm{OD}_{600}$ of 0.02 in $1 \mathrm{~mL} \mathrm{M9-complete} \mathrm{with} 0.2 \% \mathrm{w} / \mathrm{v}$ carbon source (see Table 1 for the carbon sources used) in a 48 -well plate. Nutrient broth was used as a positive control, and M9-complete without carbon source was used as a negative control. Bacteria were grown in a multimode temperature-controlled plate reader (Tecan Spark), which was used to monitor bacterial growth based on automated OD measurements over time for $72 \mathrm{~h}$ at $35^{\circ} \mathrm{C}$, measuring $\mathrm{OD}_{600}$ every $20 \mathrm{~min}$.

Talonic acid was synthesized from commercially available 2,3:5,6-Di-O-isopropylidene-D-talonoic acid-1,4-lactone in two steps (Supplementary Fig. S1), according to the following procedure: D-talono-1,4-lactone: TFA was added to a solution of 2,3:5,6-Di-O-isopropylidene-D-talonoic acid-1,4lactone $(532 \mathrm{mg}, 2.06 \mathrm{mmol})$ in $\mathrm{DCM} / \mathrm{H}_{2} \mathrm{O} \quad(0.25 \mathrm{M}$; DCM: $\mathrm{H}_{2} \mathrm{O}:$ TFA $\left.=100: 4: 6 \mathrm{v} / \mathrm{v}\right)$. The mixture was stirred at room temperature (rt) until the thin-layer chromatography (TLC) indicated consumption of the starting material and concentrated in vacuo. Silica column chromatography $(0 \rightarrow$ $20 \% \mathrm{MeOH}$ in EtOAc) afforded D-talono-1,4-lactone (189 mg, 52\%). ${ }^{1} \mathrm{H}$ nuclear magnetic resonance (NMR) $(500 \mathrm{MHz}, \mathrm{MeOD}) \delta 4.66(\mathrm{~d}, J=5.6 \mathrm{~Hz}, 1 \mathrm{H}), 4.51(\mathrm{~d}$, $J=1.7 \mathrm{~Hz}, 1 \mathrm{H}), 4.36(\mathrm{~d}, J=5.6 \mathrm{~Hz}, 1 \mathrm{H}), 3.83(\mathrm{td}, J=6.9$,
Table 1. Carbon Sources Used

\begin{tabular}{|c|c|c|}
\hline Carbon source & Purchased from & Order No. \\
\hline $\begin{array}{l}\text { DL-Glyceric acid } \\
\text { (20\% in water) }\end{array}$ & $\begin{array}{l}\text { Santa Cruz } \\
\text { Biotechnology }\end{array}$ & SC-486321 \\
\hline D-Threitol & Sigma-Aldrich & $377619-250 \mathrm{MG}$ \\
\hline L-Threitol & Sigma-Aldrich & 298875-1G \\
\hline Erythritol & Sigma-Aldrich & PHR1479-1G \\
\hline DL-Tartaric acid & Sigma-Aldrich & T400-25G \\
\hline $\begin{array}{l}\text { meso-Tartaric } \\
\text { acid monohydrate }\end{array}$ & Sigma-Aldrich & $95350-5 \mathrm{G}$ \\
\hline $\begin{array}{l}\text { D-Threonic acid } \\
\text { lithium salt }\end{array}$ & Sigma-Aldrich & 79272-50MG \\
\hline $\begin{array}{l}\text { D-Arabinonic acid, } \\
\text { sodium salt }\end{array}$ & Sigma-Aldrich & 00033-100MG \\
\hline $\begin{array}{l}\text { D-Lyxonic acid, } \\
\text { potassium salt }\end{array}$ & $\begin{array}{l}\text { Toronto Research } \\
\text { Chemicals }\end{array}$ & L489950_2,5g \\
\hline $\begin{array}{l}\text { D-Gluconic acid, } \\
\text { sodium salt }\end{array}$ & Sigma-Aldrich & G9005-500G \\
\hline Glucose & Merck & MERC1.08337.0250 \\
\hline
\end{tabular}

$1.8 \mathrm{~Hz}, 1 \mathrm{H}), 3.63-3.51(\mathrm{~m}, 2 \mathrm{H}) .{ }^{13} \mathrm{C} \mathrm{NMR}(126 \mathrm{MHz}, \mathrm{MeOD})$ $\delta$ 177.47, 85.04, 71.08, 70.63, 68.73, 61.86. D-talonic acid sodium salt: D-talono-1,4-lactone $(170 \mathrm{mg}, 0.95 \mathrm{mmol})$ was dissolved in $\mathrm{H}_{2} \mathrm{O}(0.3 \mathrm{M})$. $\mathrm{NaOH}(38.2 \mathrm{mg}, 1 \mathrm{eq})$ was added, and the mixture was stirred at rt. After the TLC indicated consumption of the starting material, the mixture was lyophilized to D-talonic acid sodium salt (205 mg, 99\%). ${ }^{1} \mathrm{H}$ NMR $\left(500 \mathrm{MHz}, \mathrm{D}_{2} \mathrm{O}\right) \delta 4.23(\mathrm{~d}, J=3.0 \mathrm{~Hz}, 1 \mathrm{H}), 4.01$ (dd, $J=8.5$, $3.0 \mathrm{~Hz}, 1 \mathrm{H}), 3.96(\mathrm{ddd}, J=7.3,5.4,1.9 \mathrm{~Hz}, 1 \mathrm{H}), 3.80$ (dd, $J=8.5,1.9 \mathrm{~Hz}, 1 \mathrm{H}), 3.68(\mathrm{dd}, J=6.3,2.6 \mathrm{~Hz}, 2 \mathrm{H}) .{ }^{13} \mathrm{C} \mathrm{NMR}$ $\left(126 \mathrm{MHz}, \mathrm{D}_{2} \mathrm{O}\right) \delta 178.31,73.81,72.58,70.60,70.04,63.15$.

\subsection{Culturing for animal experiments}

Cultures for animal experiments were grown in M9 medium with $3.739 \mathrm{mM} \mathrm{NH}_{4} \mathrm{Cl}$ (1/5 from the original) to achieve a $\mathrm{C}: \mathrm{N}$ ratio of $\sim 16$. K. pneumoniae were plated on nutrient-broth (Difco) agar plates. After o/n growth at $35^{\circ} \mathrm{C}$, several colonies were resuspended in M9-complete-low $\mathrm{N}$ ([M9 minimal salt medium with low $\mathrm{N}$ with $0.1 \mathrm{~m} M \mathrm{CaCl}_{2}, 2 \mathrm{mM} \mathrm{MgSO}_{4}$, and $\left.0.02 \mathrm{~m} M \quad \mathrm{Fe}(\mathrm{III}) \mathrm{Cl}_{3}\right], \quad 47.76 \mathrm{~m} M \quad \mathrm{Na}_{2} \mathrm{HPO}_{4}, \quad 22.044 \mathrm{mM}$ $\mathrm{KH}_{2} \mathrm{PO}_{4}, 8.556 \mathrm{~m} M \mathrm{NaCl}$, and $0.748 \mathrm{~m} M \mathrm{NH}_{4} \mathrm{Cl}$, without carbon source). Subsequently, $\mathrm{OD}_{600}$ was measured, and bacteria were added to a start $\mathrm{OD}_{600}$ of 0.02 in 5 wells, each containing $1 \mathrm{~mL}$ culture medium (M9-complete with $0.2 \% \mathrm{w} / \mathrm{v}$ carbon source) on a 48 -well plate. Cultures with glucose and gluconic acid were grown overnight and cultures with glyceric acid were grown for $72 \mathrm{~h}$. After growth, wells containing the same carbon source were pooled and $\mathrm{OD}_{600}$ was measured, to make the dilutions for in vivo infection experiments. In the other growth experiments described in this article, the content of the wells was not pooled, as the separate wells were regarded as duplicate or triplicate measurements. The $\mathrm{OD}_{600}$ values were transformed into colony-forming unit (CFU; OD $6001=4 \times 10^{9}$ $\mathrm{CFU} / \mathrm{mL}$ ). Cultures were diluted to a CFU of $5 \times 10^{7} / \mathrm{mL}$ in M9-complete-lowN containing the same carbon source.

\subsection{Characterization of K. pneumoniae lipopolysaccharide}

$K$. pneumoniae were grown under the same conditions as those used for the animal experiments. After growth, bacteria were collected and resuspended in $150 \mu \mathrm{L}$ lysis buffer $(60 \mathrm{mM}$ 
Tris, $10 \mathrm{~m} M$ EDTA, $2 \%$ SDS, pH 6.8). Subsequently, $30 \mu \mathrm{L}$ proteinase $\mathrm{K}$ (Roche) was added, and the sample was incubated for $24 \mathrm{~h}$ at $37^{\circ} \mathrm{C}$. The major component found in the outer membrane of gram-negative bacteria, $K$. pneumoniae lipopolysaccharide (LPS), was precipitated by mixing the sample with $20 \mu \mathrm{L} 3 M$ Na-acetate and $400 \mu \mathrm{L} 100 \% \mathrm{EtOH}$. It was incubated for $1 \mathrm{~h}$ at $-20^{\circ} \mathrm{C}$ and centrifuged for $5 \mathrm{~min}$ at $15,000 \times g$. Supernatant was removed, and the pellet was washed twice with $70 \% \mathrm{EtOH}$. After the final wash, the pellet was resuspended in $180 \mu \mathrm{L}$ water. Samples were run on a $12 \%$ Tris$\mathrm{HCl}$ sodium dodecyl sulfate polyacrylamide gel electrophoresis (SDS-PAGE) gel and silver stained, as described in previous research (Langereis and Weiser, 2014).

\subsection{Transmission electron microscopy analysis}

To comply with safety regulations, all bacterial cultures were prefixed for $20 \mathrm{~min}$ with $4 \%$ PFA. Cells were gently pelleted (600-RCF $5 \mathrm{~min}$ ), supernatant was removed, and the pellet was resuspended in the remaining medium. Subsequently, samples with a thickness of $100 \mu \mathrm{m}$ were highpressure frozen using the $3 \mathrm{~mm}$ platelet system in an HPM100 high-pressure freezer (Leica Microsystems). Samples were freeze-substituted in anhydrous acetone containing 2\% $\mathrm{OsO}_{4}$, $1 \% \mathrm{H}_{2} \mathrm{O}$, and $0.2 \%$ uranyl acetate, as described in previous research (van Niftrik et al., 2008), and subsequently embedded in Epon resin. Ultrathin $60 \mathrm{~nm}$ sections were cut on a Reichert/Jung Ultracut ultramicrotome and collected 100\# copper grids with a carbon-coated formvar support film. Grids were poststained with $0.5 \%$ uranyl acetate and Reynolds lead citrate before analysis in the JEOL-1400 Flash transmission electron microscope operating at $120 \mathrm{kV}$.

\subsection{Peripheral blood mononuclear cell and monocyte isolation}

Buffy coats (concentrated leukocyte suspensions obtained from whole human blood) from healthy donors were obtained after written informed consent (Sanquin Blood Bank, Nijmegen, Netherlands). Samples were anonymized to safeguard donor privacy. The peripheral blood mononuclear cell (PBMC) fraction consists of any peripheral blood cell having a round nucleus. These cells are lymphocytes (T cells, B cells, NK cells) and monocytes. Isolation of PBMCs was performed by differential density centrifugation over Ficoll-Paque (GE Healthcare). Percoll isolation of monocytes was performed as described in previous research (Repnik et al., 2003). Briefly stated, 150 $200 \times 10^{6}$ PBMCs were layered on top of a hyperosmotic Percoll solution and centrifuged for $15 \mathrm{~min}$ at $580 \times \mathrm{g}$. The interphase layer was isolated, and cells were washed with cold phosphatebuffered saline (PBS). Cells were resuspended in RPMI medium with Dutch modification (Invitrogen) supplemented with $50 \mu \mathrm{g} / \mathrm{mL}$ gentamicin, $2 \mathrm{~m} M$ GlutaMAX, and $1 \mathrm{~m} M$ pyruvate, and counted. An additional purification step was added by adhering Percoll-isolated monocytes to polystyrene flat-bottom plates (Corning) for $1 \mathrm{~h}$ at $37^{\circ} \mathrm{C}$. A washing step with warm PBS was then performed to yield maximal purity.

\subsection{Stimulation experiments}

A total of $5 \times 10^{5} \mathrm{PBMCs} / \mathrm{mL}$ or $1 \times 10^{5}$ monocytes were added to flat-bottom 96-well plates (Greiner). Cells were stimulated with $1 \times 10^{6} / \mathrm{mL}$ live or beta-propiolactone (BPL)inactivated bacteria. Supernatants from monocytes were col- lected $24 \mathrm{~h}$ after stimulation and stored at $-20^{\circ} \mathrm{C}$. For the receptor-blockade experiments, before bacterial stimulation, monocytes were preincubated for $1 \mathrm{~h}$ with $100 \mathrm{ng} / \mathrm{mL}$ Bartonella quintana LPS (Popa et al., 2007), $10 \mu \mathrm{g} / \mathrm{mL}$ TLR2-blocking antibody (anti-TLR2) and its control IgA1 (InvivoGen, San Diego, CA), $10 \mu \mathrm{g} / \mathrm{mL}$ TLR5-blocking antibody (anti-TLR5; InvivoGen), and the IgA2 isotype control (InvivoGen).

\subsection{Assessment of cytokine production}

Production of human IL-1 $\beta$, IL-6, TNF $\alpha$, IL-10, and IFN $\gamma$ in cell culture supernatants was measured by using human IL-1 $\beta$, IL-6, TNF $\alpha$, IL-10, and IFN $\gamma$ enzyme-linked immunosorbent assay kits (R\&D Systems, Minneapolis, MN) following the instructions of the manufacturer.

\subsection{Killing assays}

K. pneumoniae were exposed to neutrophils for $2 \mathrm{~h}$ in a 2:1 ratio of pathogens to neutrophils. The neutrophils were then lysed with Triton X-100 solution $0.5 \%$, and the number of surviving bacteria was assessed on agar plates. Killing activity was expressed as the percentage of bacteria surviving in the presence of neutrophils, compared with yeast or bacteria surviving in the absence of neutrophils.

\subsection{In vivo model of infection}

All animals were housed in cages under constant temperature $\left(21^{\circ} \mathrm{C}\right)$ and humidity, with a constant 12-h light/dark cycle. All animals had ad libitum access to food and water. Analgesia was achieved by the administration of meloxicam $5 \mathrm{mg} / \mathrm{kg}$ subcutaneously. The animal studies were approved by the Greek veterinary directorate under the protocol number 7467 on December 24, 2013. Six-week-old male C57BL/6 mice were infected by an intravenous dose of $1 \times 10^{5} \mathrm{~K}$. pneumoniae through a lateral tail vein. Five mice from each group were sacrificed at specified time points. The mice were randomized into groups, based on a random number table. The mice were numbered by tail marking. Sacrifice was performed by the administration of ketamine $(300 \mathrm{mg} / \mathrm{kg}$ ) and xylazine $(30 \mathrm{mg} / \mathrm{kg})$ intraperitoneally, followed by cervical dislocation.

\subsection{Assessment of bacterial burden}

Organs were aseptically removed through an abdominal incision, weighed, and homogenized in PBS. K. pneumoniae CFUs were determined by plating organ homogenates in serial dilutions on agar plates. CFUs were counted after growth for $24 \mathrm{~h}$ at $37^{\circ} \mathrm{C}$.

\subsection{Statistical analysis}

In the in vitro experiments, each grouped paired sample was compared individually with the control group, followed by a Wilcoxon signed-rank test (nonparametric, paired samples) on the results. In the in vivo experiments, we performed one-way analysis of variance with no matching or pairing, and not assuming normal distribution. A $p$-value of $<0.05$ was designated as the threshold for statistical significance.

\section{Results}

To investigate the hypothesis that terrestrial bacteria could survive and adapt in an environment with water, 
simple carbohydrates, inorganic nitrogen, and phosphorus (such as those isolated from meteorites), we assessed whether a group of nonfastidious bacterial species found in the terrestrial environment (i.e., $P$. aeruginosa, B. cepacia, $K$. pneumoniae, and $S$. marcescens) were able to adapt to a minimal medium containing inorganic nitrogen (ammonium), phosphorus (phosphate), sulfur (sulfate), iron, and water, supplemented exclusively with carbohydrates identified in carbonaceous meteorites (e.g., the Murchison meteorite; see Cooper et al., 2001). Strikingly, the four species were able to grow in a variety of media, with substrates of 3 , 4, 5, and 6 carbon atoms (as found on carbonaceous meteorites), including DL-glyceric acid, D-threitol, erythritol, DLtartaric acid, meso-tartaric acid, D-arabinonic acid, and D-gluconic acid (Fig. 1A, B). Growth, as measured by $\mathrm{OD}_{600}$, was reduced relative to a rich medium containing nutrient broth, and it varied between the meteorite sugars, with DLglyceric acid and D-gluconic acid being the most favorable carbon sources supporting bacterial growth, in addition to the abundant terrestrial sugar glucose, which was included as a positive control (Fig. 1B). Importantly, adaptation to the minimal medium resulted in lower baseline $\mathrm{pH}$ levels, compared with those measured with standard nutrient broth. However, the four bacterial species adapted to these more acidic conditions and grew without causing substantial variations in the final $\mathrm{pH}$ of the media (Supplementary Fig. S2A). This result was likely caused by the excess of ammonia liberated from $\mathrm{N}$-containing organic compounds. Given the possible effect of the ratio of the number of carbon atoms to the amount of nitrogen atoms on growth potential, two different C:N ratios were assessed $(\sim 3$ and $\sim 16)$ (Fig. 1C). Only a slight improvement of growth was measured at a higher C:N ratio. Shifting the carbon source between DLglyceric acid, D-gluconic acid, and glucose did not impair bacterial growth, thus indicating that bacteria retained their full adaptation and plasticity potential, even in restrictive culture conditions (Supplementary Fig. S2B).

In a set of follow-up experiments, we sought to determine whether the adaptation of bacteria to nonterrestrial conditions would change their interaction with cells of the human immune system. We grew the various bacterial species in minimal medium supplemented with DL-glyceric acid, D-gluconic acid, and D-glucose, and were subsequently incubated with freshly isolated human monocytes or human PBMCs. The proinflammatory cytokines IL-1 $\beta$, IL-6, and $\mathrm{TNF} \alpha$ produced by human monocytes or PBMCs are commonly used as markers of innate immune response to bacterial stimulation. In this case, they were used as markers for the strength of the inflammatory response against the bacteria grown in meteorite sugars. Among the species tested, $K$. pneumoniae showed the greatest differences in the induction of cytokine production by human cells, depending on its growth on terrestrial (glucose) or meteorite (DLglyceric acid, D-gluconic acid) sugars. More specifically, the stimulation of human PBMCs (containing a mix of lymphocytes and monocytes) with live $K$. pneumoniae induced a higher production of IL-1 $\beta$ and $\mathrm{TNF} \alpha$ when the bacteria were grown in DL-glyceric acid, with lower IL-6 production after growth in gluconic acid (Fig. 2A). Importantly, the induction of IFN $\gamma$ production in PBMCs stimulated by $B$. cepacia was remarkably higher after growth in minimal medium supplemented with DL-glyceric acid or glucose
(Supplementary Fig. S3A). Stimulation of human monocytes with $K$. pneumoniae grown on DL-glyceric acid induced greater production of IL-1 $\beta$, IL- 6 , and TNF $\alpha$ than was the case for bacteria exposed to standard nutrient broth, while $K$. pneumoniae grown on D-gluconic acid and glucose also induced more $\mathrm{TNF} \alpha$ production by human monocytes (Fig. 2B). Moreover, growth on D-gluconic acid led to a reduction in the amounts of IL-1 $\beta$ and TNF $\alpha$ secreted by human monocytes stimulated with $B$. cepacia (Supplementary Fig. S3B). These variations prove that the adaptation of bacteria to different environments can also cause alterations in the interaction with immune cells and changes in the induction of cytokine responses.

The immune response increased upon recognition of the pathogen-associated molecular patterns (PAMPs) by the pattern-recognition receptors (PRRs) expressed on the surface of immune cells (Janeway and Medzhitov, 2002). The variations observed in the induction of the immune responses by the various bacteria could be caused by alterations in the bacterial cell envelope structure. Our next question concerned whether the supplementation of the various carbonaceous sources would lead to changes in the structure of PAMPs and the architecture of the cell envelope of the bacteria. Aberrant structures induced by exposure to an uncommon carbon source would alter the degree of exposure of various structures of the cell envelope, making them more or less accessible to the PRR of the immune cells. To elucidate this, we assessed the cytokine responses in human monocytes that had been exposed to bacteria inactivated by BPL, a molecule that preserves the integrity of the cell envelope. Note that the use of live or inactivated bacteria can cause differences in the production of inflammatory cytokines by immune cells (Blander and Barbet, 2018). In this case, the loss of bacterial viability caused by BPL increased the production of IL- $1 \beta$, compared with live bacteria (Fig. 2C). However, the inactivation of the bacteria did not abrogate the changes in cytokine responses that were induced by bacteria grown in nutrient broth and those cultured in minimal medium supplemented with exo-sugars (Fig. 2C and Supplementary Fig. S4).

Given that $K$. pneumoniae is a gram-negative pathogen, LPS was likely to be the most immunogenic molecule in the cell envelope of these bacteria. Indeed, the blockage of TLR4 - the cellular receptor for LPS - led to the abrogation of the differences in cytokine production induced by the bacteria grown in the various exo-sugars, while the blockage of the receptors for other cell-envelop components of the bacteria (e.g., TLR2, the receptor for lipoproteins and lipoteichoic acid, or TLR5, the receptor for flagellin) did not induce any remarkable changes (Fig. 3A and Supplementary Fig. S4). We therefore concluded that the differences observed were due mainly to changes in the recognition of LPS. In a set of followup experiments, we assessed whether changes in LPS structure or the accessibility of LPS to TLR4 was responsible for the difference in the recognition of $K$. pneumoniae grown in various sugar-like compounds. Silver-stained PAGE analysis of LPS from $K$. pneumoniae grown in minimal media with the different carbon sources did not suggest the presence of qualitative differences (Fig. 3B). These data did suggest that the differences in immunogenicity were due to differences in accessibility to the cell envelope of the bacteria, rather than to changes in the structure of bacterial components. 
A

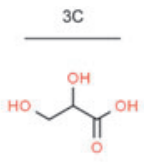

DL-Glyceric acid

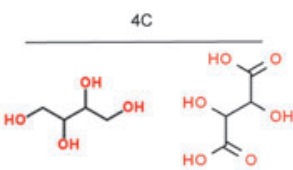

D/L-Threitol and DL-Tartaric and erythritol

mesotartaric acid

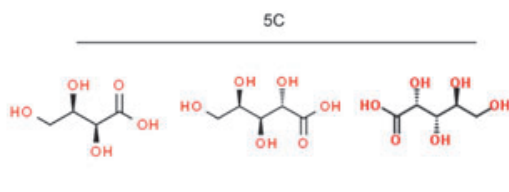

D-Threonic acid

D-Arabinonic acid



B
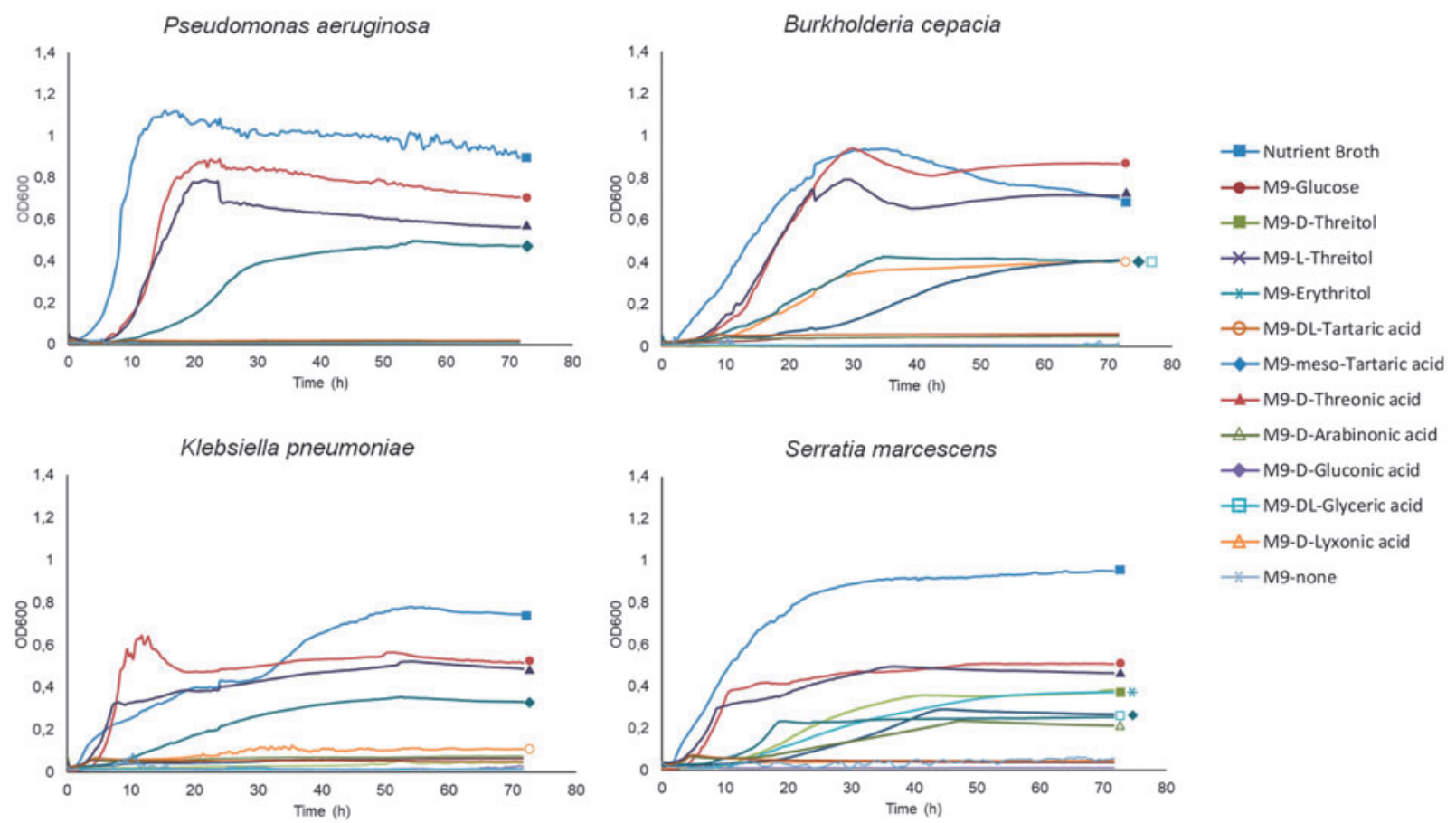

$\triangle$ M9-D-Arabinonic acid

$\neg$ M9-D-Gluconic acid

—-M9-DL-Glyceric acid

$\triangle$ M9-D-Lyxonic acid

- M9-none

C

Max ODs, average C:N ratio of $\sim 3$

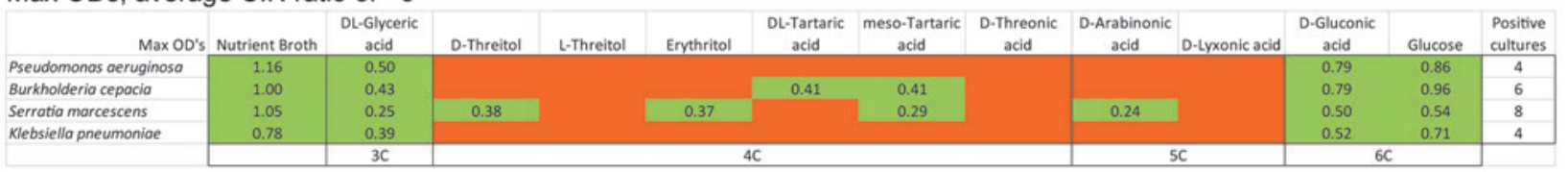

Max ODs, average C:N ratio of $\sim 16$

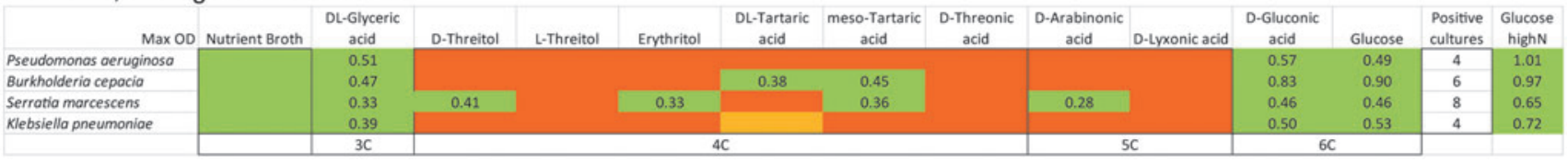

FIG. 1. Environmental bacteria are able to grow using extraterrestrial carbonaceous sources. (A) Structures of sugar derivatives identified in meteorites used throughout this study. (B) Growth curves for Pseudomonas aeruginosa, Burkholderia cepacia, Klebsiella pneumoniae, and Serratia marcescens in M9 medium supplemented with sugars described in (A). (C) Maximal optical densities $\left(\mathrm{OD}_{600}\right)$ for bacterial growth at $\mathrm{C}: \mathrm{N}$ ratios of $\sim 3$ and $\sim 16$ for the four species studied. $\mathrm{OD}_{600}$, optical density at $600 \mathrm{~nm}$.

In light of these findings, we performed transmission electron microscopy to study the potential structural differences in the cell envelope of $K$. pneumoniae. The complexity of the cell envelope was clearly diminished in bacteria cultured with D-gluconic acid or DL-glyceric acid, compared with those supplemented with glucose (Fig. 3C). In bacteria grown in D-gluconic acid or in DL-glyceric acid, the width and density of the glycocalyx structure were reduced and less organized than in the case in the glucose-grown bacteria, in which the glycocalyx thickness of all cells was uniform (Fig. 3D). In addition, lipid droplets (electron light areas in the cytoplasm) were observed in the bacteria grown on DL-glyceric. This was most likely due to storage of DL-glyceric acid as a neutral lipid.

The bacterial adaptation process that causes structural modifications in the cell envelope may also cause changes in pathogenicity, given that cytokines are very important 

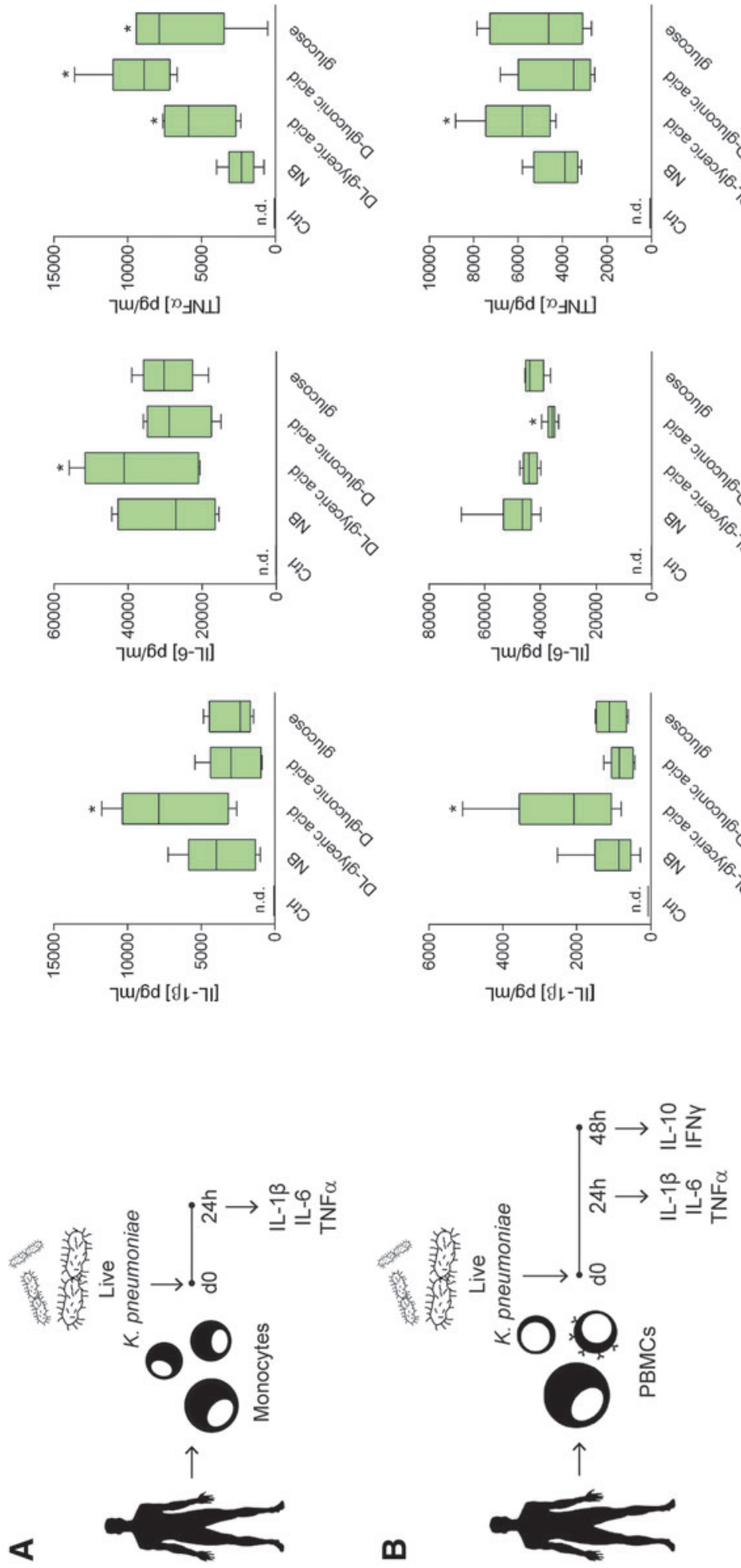

음
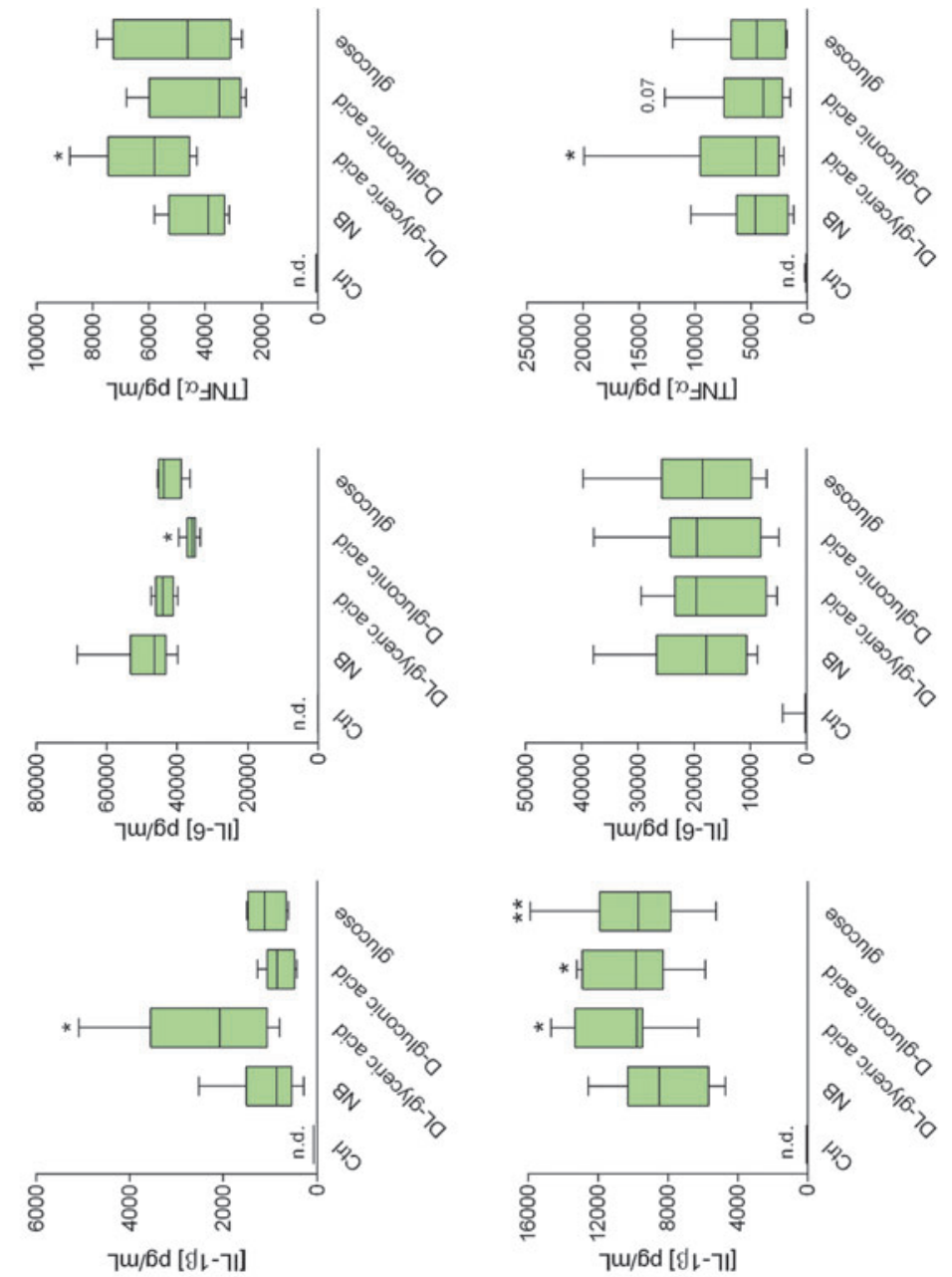

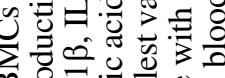

老 สี ชิํㅡㄹ

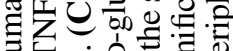

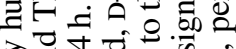

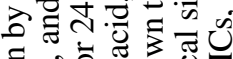
。ี

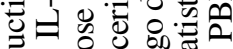

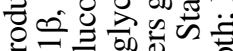

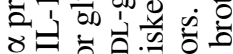

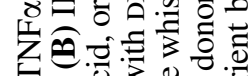

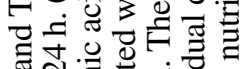

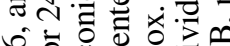

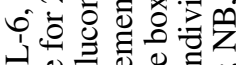
$\exists$ o

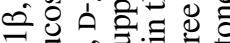

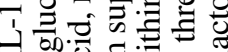
< - क्षे 胥

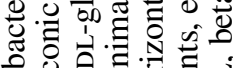
论

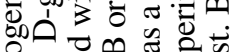

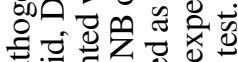
柁

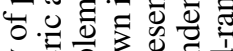

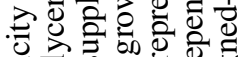

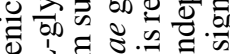

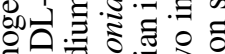

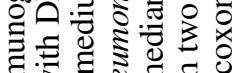

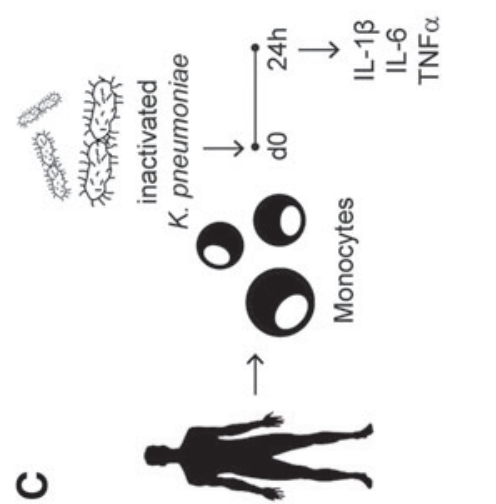

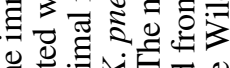
E s

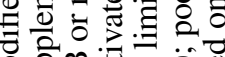

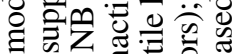

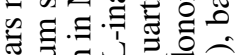

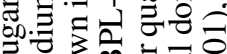
के

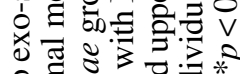

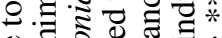

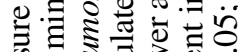
o

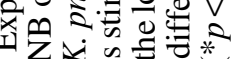

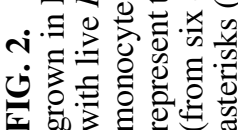


A

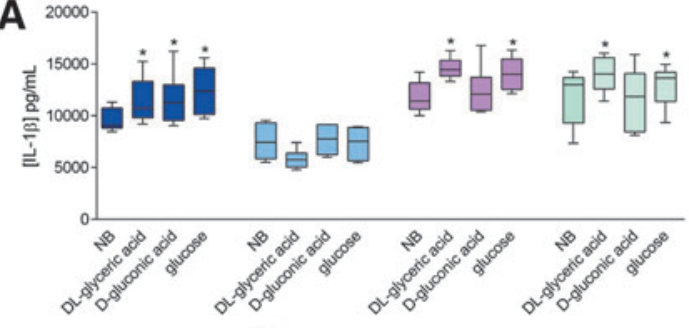

control

$\alpha$-TLR2

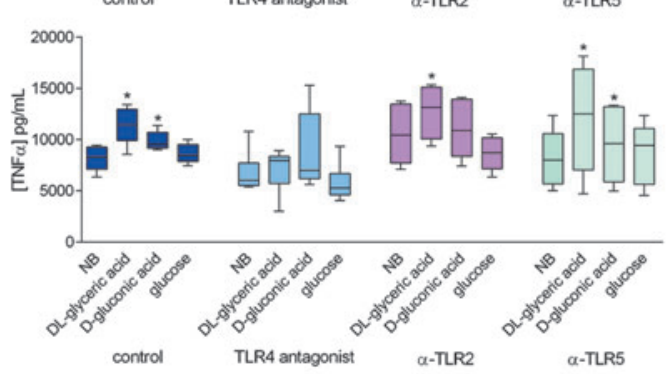

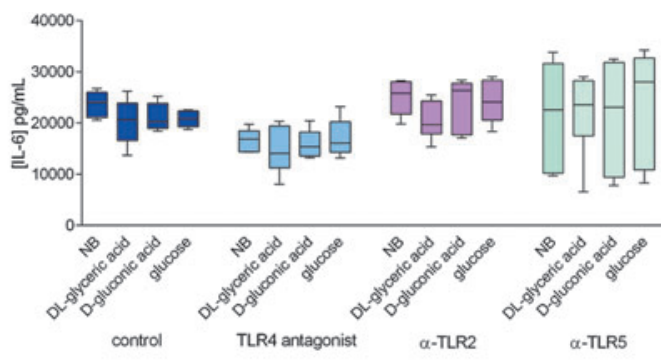

B

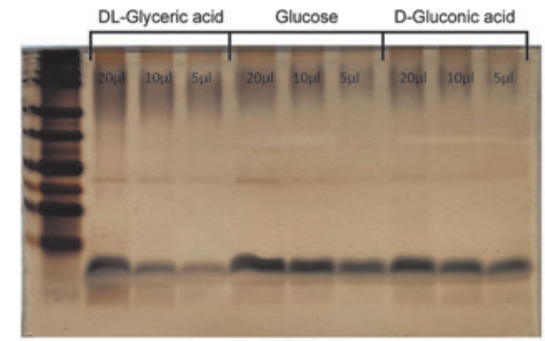

C glucose
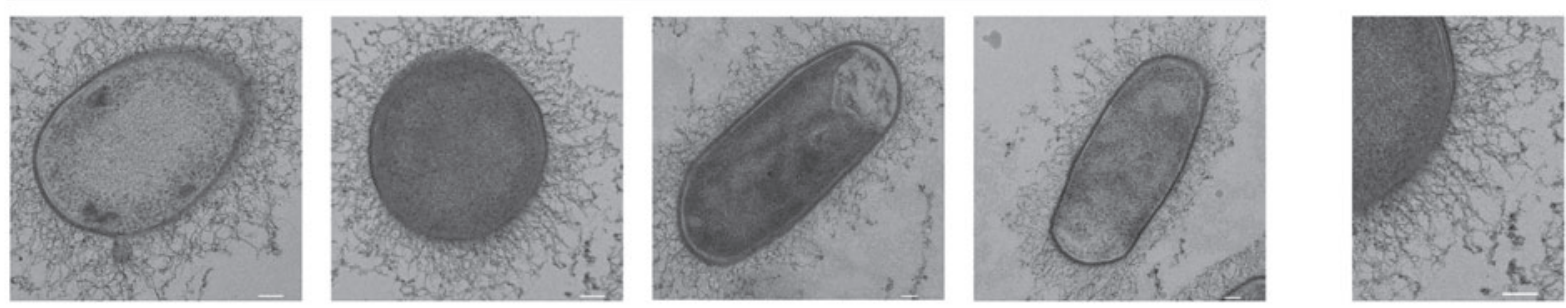

\section{DL-glyceric}
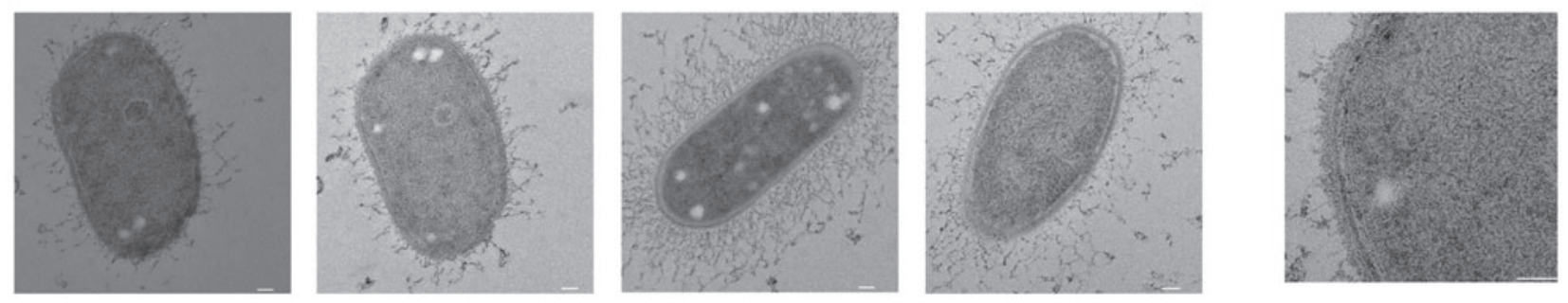

\section{D-gluconic}
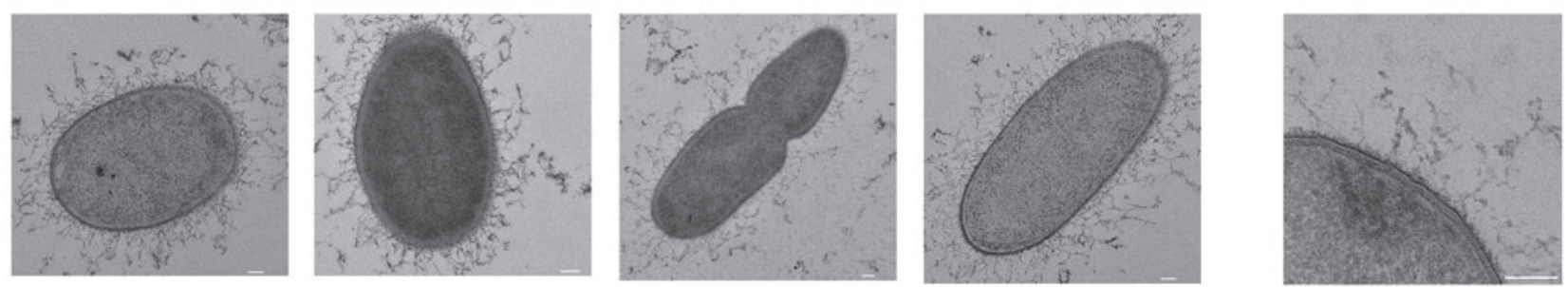

FIG. 3. Growth on exo-sugars modifies the cell-envelope structure of $K$. pneumoniae. (A) IL-1 $\beta$, IL-6, and TNF $\alpha$ production by human monocytes treated with Bartonella quintana LPS, $\alpha$-TLR2, or $\alpha$-TLR5 and stimulated with BPL-inactivated $K$. pneumoniae grown in NB or minimal medium supplemented with DL-glyceric acid, D-gluconic acid, or glucose for $24 \mathrm{~h}$. The box limits represent the lower and upper quartile limits. The median is represented as a horizontal line within the box. The whiskers go down to the smallest value and up to the largest value: $n=6$ (from six different individual donors); pooled from two independent experiments, each with three individual donors. Statistical significance with respect to NB levels is indicated by asterisks $(* p<0.05)$, based on the Wilcoxon signed-rank test. Controls for the experiment are shown in Supplementary Fig. S4. (B) Silver-stained PAGE gel for LPS extracted from the cell envelope from K. pneumoniae grown in minimal medium supplemented with DL-glyceric acid, D-gluconic acid, or glucose for $24 \mathrm{~h}$ (LPS = low-molecular-weight section of the gel). (C, D) Transmission electron micrographs for $K$. pneumoniae grown in minimal medium supplemented with DL-glyceric acid, D-gluconic acid, or glucose for $24 \mathrm{~h}$. In (D), the first images corresponding to glucose and DL-glyceric acid are enlarged sections from the images shown in (C). All scale bars represent $100 \mathrm{~nm}$. LPS, lipopolysaccharide. 
A

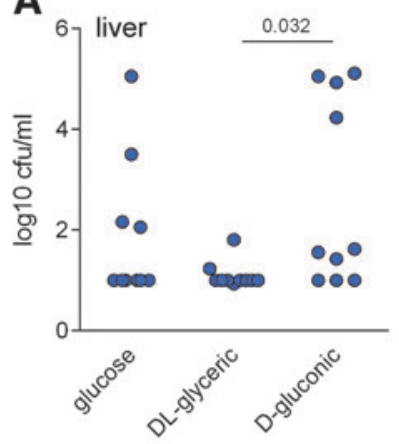

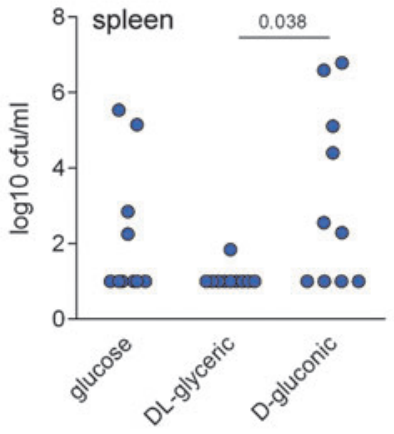

B

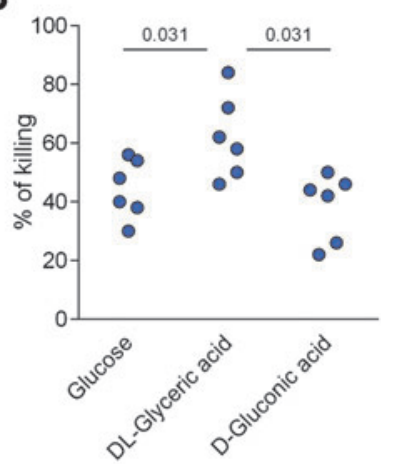

C

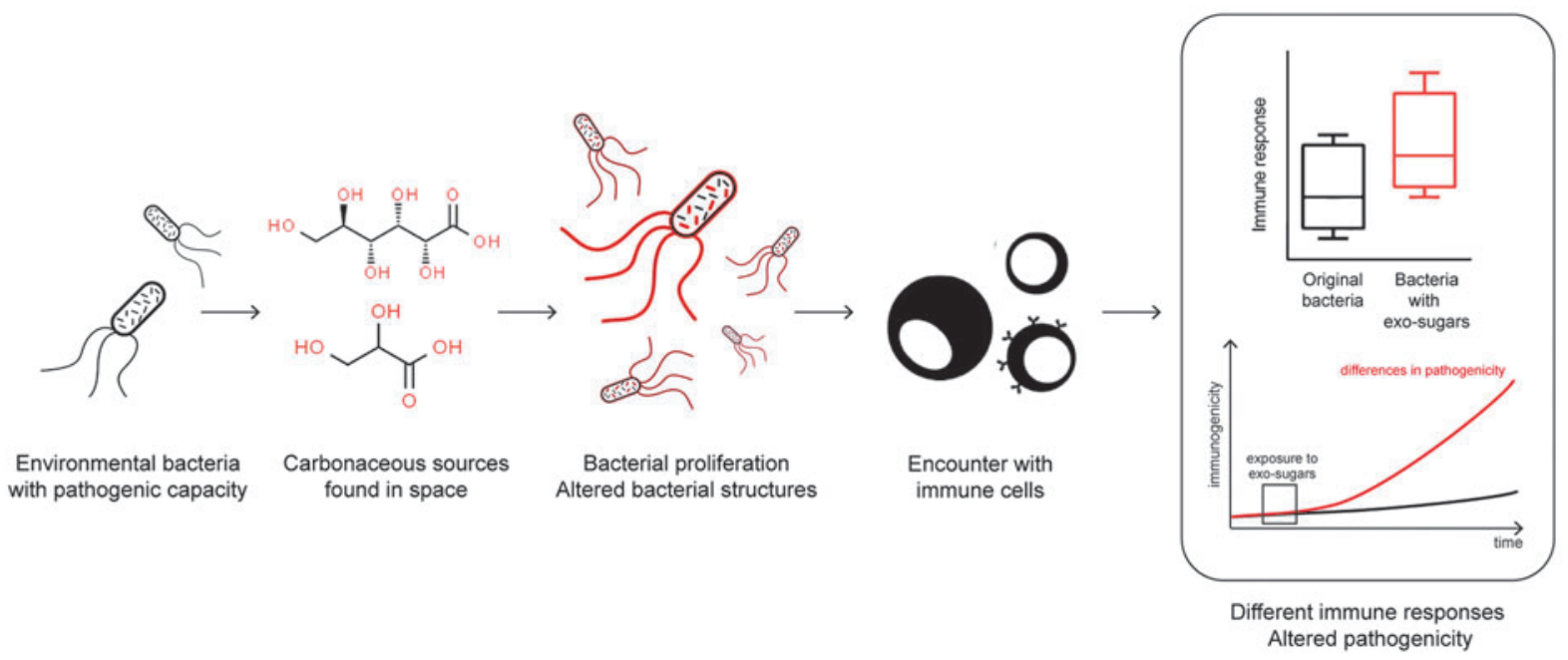

FIG. 4. Exposure to extraterrestrial carbon sources alters the in vivo pathogenicity of $K$. pneumoniae. (A) Bacterial burden measured in the liver, spleen, and lung of C57BL/6 mice injected intravenously with $K$. pneumoniae grown in minimal medium supplemented with DL-glyceric acid, D-gluconic acid, or glucose, 7 days after the challenge (mean \pm SEM, $n=6$; similar results were obtained in two independent experiments); Kruskal/Wallis test. Each dot represents one mouse. (B) Bactericidal activity of neutrophils isolated from human blood and exposed to K. pneumoniae grown in minimal medium supplemented with DL-glyceric acid, D-gluconic acid, or glucose for $2 \mathrm{~h}$ (mean \pm SEM, $n=6$; similar results were obtained in two independent experiments); Wilcoxon signed-rank test. (C) Overview of the modifications in the cell-envelope structure occurring in environmental pathogenic bacteria grown using carbonaceous sources available in space and their consequences for immunogenicity. SEM, standard error of the mean.

components of host defense. To test this hypothesis, we performed intravenous infection in mice with $K$. pneumoniae cultured on minimal medium supplemented with DLglyceric acid, D-gluconic acid, and glucose (C:N ratio $\sim 16)$. We observed significant variations in the bacterial burden found in the liver and spleen after 7 days of infection for $K$. pneumoniae grown in DL-glyceric acid, compared with the bacteria supplemented with D-gluconic acid, which presented a degree of infection more similar to the bacteria grown on glucose (Fig. 4A). Bacterial burden measured in the lung followed the same direction, although without reaching statistical significance. Of note, $K$. pneumoniae in DL-glyceric acid induced the strongest cytokine responses by monocytes and PBMCs of all the various carbon sources tested (Fig. 2). The reduced bacterial burden observed in vivo was likely due to the stronger induction of the immune response. Accordingly, the exposure of bacteria to human neutrophils showed that those grown with D-glyceric acid were more susceptible to the microbicidal actions of these cells (Fig. 4B). Taken together, these results suggest that the structural differences in the cell envelope of $K$. pneumoniae that were induced by the growth in different carbonaceous sources isolated from meteorites led to alterations in the immunogenicity and pathogenic potential of the microorganism (Fig. 4C).

\section{Discussion}

In the years to come, humans will be traveling to other planets, with the goal of reaching Mars and other planets and bodies. Terrestrial organisms will inevitably be taken along on these journeys, as hitchhikers on the bodies of astronauts or the scientific instruments. These organisms could adapt and grow in the new environments, subsequently recolonizing spacecraft and equipment and potentially infecting astronauts and others upon their return to Earth. Collectively, our results indicate that environmental bacteria, which could potentially contaminate materials used in space exploration, have the 
ability to adapt, grow, and reproduce under nutritional conditions that could potentially be encountered on nonterrestrial bodies in the solar system.

The bacteria are nevertheless able to adapt and use these nutritional sources to grow and proliferate. This also causes structural changes that produce differences in the recognition of these bacteria by the cells of the immune system, also inducing changes in the pathogenicity of the bacteria. These important aspects should be considered in future studies.

While being able to use sugar-like compounds identified in carbonaceous meteorites, the modified pathogenic bacteria retained their ability to infect organisms and induce immune responses. However, the major changes in the restrictive growth environments also produced changes in the cellenvelope structure, resulting in inefficient capacity to mask immunogenic structures (e.g., LPS). This is likely to facilitate the ability of the PRRs in the immune system to recognize cellenvelope structures (e.g., LPS), thereby leading to higher cytokine responses, strong induction of immune responses, and reduced pathogenicity, relative to the original microorganisms grown under standard conditions. The fact that the adaptation of microorganisms to new environmental sources induces changes in their pathogenicity has been supported by earlier investigations. Previous studies have indicated that a high concentration of nutritional resources favors the pathogenicity of environmental bacteria (e.g., S. marcescens) (Ketola et al., 2016). The exposure of the fungus Candida albicans to lactate instead of glucose modifies the masking of antigenic structures present on the cell envelope, altering their recognition by immune cells (Ballou et al., 2016) in a manner similar to what has been described here. The potential colonization of space bodies by terrestrial bacteria is a concern that has already been taken into account, as in the case of the Cassini mission. Briefly summarized, the Cassini was forced to burn in the atmosphere of Saturn to avoid the potentially disastrous consequences of crashing into its satellite Enceladus. Despite the fact that the vessel had spent 13 years in orbit around Saturn, it was considered that some terrestrial microorganisms could have survived and adapted to the Earth-like conditions of Enceladus (liquid water and heat under the icy surface). For this reason, the mission had to ensure that terrestrial bacteria did not colonize this satellite. Our results support these concerns and highlight the survival possibilities of terrestrial bacteria, as well as their potential to adapt to nutritional sources found in space. Very importantly, carbon sources in spaceships (brought with and by humans), combined with the spaceship environment (in which humans reside), may also play a crucial role in the survival of microorganisms during space trips. Stringent decontamination measures will therefore be fundamental to minimizing the possibility that other space bodies will be colonized by terrestrial microorganisms.

It is important to note several limitations of our study. First, it addresses only a limited number of species and nutritional and environmental variables. More comprehensive studies are warranted, including with regard to the molecular characterization of the specific changes that take place in the cell envelope. Second, future studies should adopt a more refined approach, which would mimic not only the availability of organic nutrients but also the atmospheric conditions on various bodies in the solar system, solar radiation, and pressure (among other nutritional and environmental variables and parameters). If potentially pathogenic bacteria were to be left in extraterrestrial environments, they could remain there for long periods of time, thus allowing for evolution and the emergence of unforeseen characteristics that could affect the overall capacity of these bacteria to colonize different environments and infect hosts.

\section{Conclusions}

This study opens a new field of research, and our results prove that human pathogenic microorganisms found in the environment can adapt to limited resources (as could potentially be found on other bodies in the solar system). Our data also demonstrate that these pathogenic bacteria can modify their pathogenic potential in response to the changed environments. While this resulted in lower pathogenicity of $K$. pneumoniae in the particular cases studied here, more comprehensive studies are needed, as the structural and immunogenicity changes undergone by bacteria may still represent a health hazard (e.g., immune-mediated reactions or allergies) both for astronauts and for those coming into contact with the material recovered from space missions. This reality demands thorough analysis to ensure the safety and integrity of future expeditions to Mars, asteroids, and other planets.

\section{Data Availability}

Data supporting the findings of this study are available within the article and Supplementary Figures S1-S5. Related data are available from the corresponding author upon request. No restrictions on data availability apply.

\section{Authors' Contributions}

J.D.-A., M.E., M.I.J., and M.G.N. designed and performed experiments and analyzed the data. J.D.-A. wrote the first draft of the article, with all authors contributing by writing and providing feedback. M.E. performed the bacterial cultures, experiments, and LPS analysis. J.D.-A. performed experiments with human cells and cytokine measurements. R.J.M. and L.N. conducted the EM studies. S.J.M. performed the synthesis of talonic acid. G.R. and E.J.G.-B. designed and performed in vivo experiments. T.J.B., P.R., J.W.M.M., and H.J.M.O.C. provided guidance and advice. M.I.J. and M.G.N. conceived ideas and oversaw the research program.

\section{Acknowledgments}

We are grateful to Sean Maldjian and Viral faisalovers for providing the figure icons for "Bacteria," as deposited on thenounproject.com.

\section{Author Disclosure Statement}

No competing financial interests exist.

\section{Funding Information}

M.G.N. was supported by a European Research Council (ERC) Advanced Grant (No. 833247) and a Spinoza grant from the Netherlands Organization for Scientific Research. H.J.M.O.C. was supported by the ERC (Advanced Grant 669371).

\section{Supplementary Material}

Supplementary Figure S1 
Supplementary Figure S2

Supplementary Figure S3

Supplementary Figure S4

Supplementary Figure S5

\section{References}

Agarwal, V.K., Schutte, W., Greenberg, J.M., Ferris, J.P., Briggs, R., Connor, S., Van de Bult, C.P., and Baas, F. (1985) Photochemical reactions in interstellar grains photolysis of $\mathrm{CO}, \mathrm{NH}_{3}$, and $\mathrm{H}_{2} \mathrm{O}$. Orig Life Evol Biosph 16:21-40.

Ballou, E.R., Avelar, G.M., Childers, D.S., Mackie, J., Bain, J.M., Wagener, J., Kastora, S.L., Panea, M.D., Hardison, S.E., Walker, L.A., Erwig, L.P., Munro, C.A., Gow, N.A.R., Brown, G.D., MacCallum, D.M., Brown, A.J.P., Brown, G.D., Gordon, S., Hardison, S.E., Brown, G.D., O’Meara, T.R., Alspaugh, J.A., Carrion, S.J., Gow, N.A.R., Hube, B., Wheeler, R.T., Fink, G.R., Wheeler, R.T., Kombe, D., Agarwala, S.D., Fink, G.R., Nett, J.E., Sanchez, H., Cain, M.T., Andes, D.R., Gantner, B.N., Simmons, R.M., Underhill, D.M., Hopke, A., Sosinska, G.J., Ene, I.V., Munro, C.A., Heilmann, C.J., Galán-Díez, M., Ene, I.V., Cheng, S.-C., Netea, M.G., Brown, A.J.P., Barelle, C.J., Owen, D.H., Katz, D.F., Ene, I.V., Marakalala, M.J., Vieira, N., Kuei, C., Maidan, M.M., Lemaire, K., Van de Velde, S., Van Dijck, P., Thevelein, J.M., Johnston, C.A., Siderovski, D.P., Leberer, E., Santos, M., Larrinoa, I.F., Karababa, M., Kelly, M.T., Desai, P.R., van Wijlick, L., Kurtz, D., Juchimiuk, M., Ernst, J.F., Hall, R.A., Bain, J.M., Flint, H.J., Scott, K.P., Louis, P., Duncan, S.H., Jacobs, I., Netea, M.G., Ferwerda, B., Iliev, I.D., Wheeler, R.T., Kupiec, M., Magnelli, P., Abeijon, C., Fink, G.R., Chen, Y.L., Lev, S., Desmarini, D., Chayakulkeeree, M., Sorrell, T.C., Djordjevic, J.T., Ene, I.V., Gravelat, F.N., Rappleye, C.A., Goldman, W.E., Noble, S.M., Johnson, A.D., Lewis, L.E., Netea, M.G., Graham, L.M., Shahana, S., Inglis, D.O., Bindea, G., and Shannon, P. (2016) Lactate signalling regulates fungal $\beta$-glucan masking and immune evasion. Nat Microbiol 2:16238.

Blander, J.M. and Barbet, G. (2018) Exploiting vita-PAMPs in vaccines. Curr Opin Pharmacol 41:128-136.

Cooper, G. and Rios, A.C. (2016) Enantiomer excesses of rare and common sugar derivatives in carbonaceous meteorites. Proc Natl Acad Sci U S A 113:E3322-E3331.

Cooper, G., Kimmich, N., Belisle, W., Sarinana, J., Brabham, K., and Garrel, L. (2001) Carbonaceous meteorites as a source of sugar-related organic compounds for the early Earth. Nature 414:879-883.

Cronin, J.R. and Pizzarello, S. (1997) Enantiomeric excesses in meteoritic amino acids. Science 275:951-955.

Janeway, C.A. and Medzhitov, R. (2002) Innate immune recognition. Annu Rev Immunol 20:197-216.

Ketola, T., Mikonranta, L., Laakso, J., and Mappes, J. (2016) Different food sources elicit fast changes to bacterial virulence. Biol Lett 12: 20150660.

Khare, B.N., Thompson, W.R., Chyba, C.F., Arakawa, E.T., and Sagan, C. (1989) Organic solids produced from simple C/H/ $\mathrm{O} / \mathrm{N}$ ices by charged particles: applications to the outer solar system. Adv Space Res 9:41-53.

Langereis, J.D. and Weiser, J.N. (2014) Shielding of a lipooligosaccharide IgM epitope allows evasion of neutrophilmediated killing of an invasive strain of nontypeable Haemophilus influenzae. mBio 5:e01478-14.

Nagler, K., Julius, C., and Moeller, R. (2016) Germination of spores of astrobiologically relevant Bacillus species in highsalinity environments. Astrobiology 16:500-512.

Nicholson, W.L., Munakata, N., Horneck, G., Melosh, H.J., and Setlow, P. (2000) Resistance of Bacillus endospores to ex- treme terrestrial and extraterrestrial environments. Microbiol Mol Biol Rev 64:548-572.

van Niftrik, L., Geerts, W.J.C., van Donselaar, E.G., Humbel, B.M., Yakushevska, A., Verkleij, A.J., Jetten, M.S.M., and Strous, M. (2008) Combined structural and chemical analysis of the anammoxosome: a membrane-bounded intracytoplasmic compartment in anammox bacteria. J Struct Biol 161:401-410.

Parkinson, C.D., Liang, M.-C., Yung, Y.L., and Kirschivnk, J.L. (2008) Habitability of enceladus: planetary conditions for life. Orig Life Evol Biosph 38:355-369.

Pering, K.L. and Ponnamperuma, C. (1971) Aromatic hydrocarbons in the Murchison meteorite. Science 173:237-239.

Pizzarello, S. and Shock, E. (2017) Carbonaceous chondrite meteorites: the chronicle of a potential evolutionary path between stars and life. Orig Life Evol Biosph 47:249-260.

Popa, C., Abdollahi-Roodsaz, S., Joosten, L.A.B., Takahashi, N., Sprong, T., Matera, G., Liberto, M.C., Foca, A., van Deuren, M., Kullberg, B.J., van den Berg, W.B., van der Meer, J.W.M., and Netea, M.G. (2007) Bartonella quintana lipopolysaccharide is a natural antagonist of Toll-like receptor 4. Infect Immun 75:4831-4837.

Pulschen, A.A., de Araujo, G.G., de Carvalho, A.C.S.R., Cerini, M.F., Fonseca, L.M., Galante, D., and Rodrigues, F. (2018) Survival of extremophilic yeasts in the stratospheric environment during balloon flights and in laboratory simulations. Appl Environ Microbiol 84: e01942-18.

Repnik, U., Knezevic, M., and Jeras, M. (2003) Simple and cost-effective isolation of monocytes from buffy coats. $J$ Immunol Methods 278:283-292.

Seckbach, J. and Oren, A. (2000) Extremophilic microorganisms as candidates for extraterrestrial life. In Proceedings SPIE4137, Instruments, Methods, and Missions for Astrobiology, Vol. 4137, edited by R.B. Hoover, SPIE Proceedings, pp. 89-95. DOI: 10.1117/12.411613.

Waite, J.H., Jr., Lewis, W.S., Magee, B.A., Lunine, J.I., McKinnon, W.B., Glein, C.R., Mousis, O., Young, D.T., Brockwell, T., Westlake, J., Nguyen, M.-J., Teolis, B.D., Niemann, H.B., McNutt, R.L., Jr., Perry, M., and Ip, W.-H. (2009) Liquid water on Enceladus from observations of ammonia and 40Ar in the plume. Nature 460:487-490.

Address correspondence to: Jorge Domínguez-Andrés Department of Internal Medicine Radboud University Medical Center Geert Grooteplein Zuid 8 6525 GA Nijmegen Netherlands

E-mail: jorge.dominguezandres@radboudumc.nl

Submitted 27 September 2019 Accepted 2 April 2020 Associate Editor: Victor Parro

\section{Abbreviations Used}

$\mathrm{BPL}=$ beta-propiolactone

$\mathrm{CFU}=$ colony-forming unit

LPS $=$ lipopolysaccharide

$\mathrm{OD}_{600}=$ optical density at $600 \mathrm{~nm}$

PAMPs $=$ pathogen-associated molecular patterns

PBMC $=$ peripheral blood mononuclear cell

PBS $=$ phosphate-buffered saline

PRRs $=$ pattern-recognition receptors 